\title{
Generation lengths of the world's birds and their implications for extinction risk
}

Jeremy P. Bird ${ }^{1,2}$, Robert Martin ${ }^{1}$, H. Reşit Akçakaya ${ }^{3, x}$, James Gilroy ${ }^{4}$, Ian J. Burfield ${ }^{1}$, Stephen Garnett $^{5}$, Andy Symes, Joe Taylor ${ }^{1}$, Çağan H. Şekercioğlu ${ }^{6,7,8}$, Stuart H. M. Butchart ${ }^{1,9}$

1. BirdLife International, David Attenborough Building, Pembroke Street, Cambridge CB2 3QZ, UK

2. Centre for Biodiversity and Conservation Science, University of Queensland

3. Department of Ecology and Evolution, Stony Brook University, New York

x. IUCN Species Survival Commission

4. School of Environmental Sciences, University of East Anglia, Norwich NR4 7TJ, UK

5. Research Institute for the Environment and Livelihoods, Charles Darwin University, Northern Territory 0909, Australia

6. School of Biological Sciences, University of Utah, 257 S 1400 E Salt Lake City, UT 84112, USA

7. Department of Molecular Biology and Genetics, Koç University, Istanbul, Turkey

8. KuzeyDoğa Derneği, Ortakapı Mah. Şehit Yusuf Bey Cad. No: 93 Kars, Turkey

9. Department of Zoology, University of Cambridge, Downing Street, Cambridge CB2 3EJ, UK

Corresponding author - Stuart H. M. Butchart, stuart.butchart@birdlife.org

Running Head - Generation lengths of the world's birds

Keywords - Red List, extinction risk, longevity, survival, species assessment

\section{Article impact statement}

Accurate generation lengths for all birds will improve assessment of extinction within the group.

This article has been accepted for publication and undergone full peer review but has not been through the copyediting, typesetting, pagination and proofreading process, which may lead to differences between this version and the Version of Record. Please cite this article as doi: $\underline{10.1111 / \text { cobi.13486. }}$.

This article is protected by copyright. All rights reserved. 


\begin{abstract}
Birds have been comprehensively assessed on the IUCN Red List more times than any other taxonomic group. However, to date, generation lengths have not been systematically estimated to scale population trends when undertaking assessments, as required by the Red List Criteria. We compiled information from major databases of published life history and trait data for all birds, and imputed missing life history data as a function of species traits using Generalized Linear Mixed Models. Generation lengths were derived for all species, based on our modelled values of age-at-firstbreeding $(F)$, maximum longevity $(L)$ and annual adult survival $(S)$. The resulting generation lengths vary from 1.42 to 27.87 years, with a median of 2.99 years. We found that most species (61\%) have generation lengths shorter than 3.33 years, meaning that the period of three generations - over which population declines are assessed under Criterion A of the Red List - was shorter than 10 years, the value used for Red List assessments of species with short generation times. For these species, our trait-informed estimates of generation length suggest that 10 years is a robust precautionary value for threat assessment. In other cases, however, for whole families, genera or individual species, generation length has a substantial impact on their estimated extinction risk, resulting in higher extinction risk in longer-lived species. While our approach is an effective means of addressing data gaps, there is some evidence that generation lengths for some species may still have been underestimated, owing to a paucity of life history data. Overall, our results will strengthen future extinction risk assessments and augment key databases of avian life history and trait data. We hope the findings stimulate future research to fill the remaining data gaps.
\end{abstract}

\title{
Introduction
}

Species' generation lengths, defined as "the average age of parents of the current cohort" (IUCN 2019), have been applied broadly within ecology as a metric of life-history variation (Gaillard et al. 2005), when evaluating responses to variable environments (Tuljapurkar et al. 2009) and for calculating rates of evolution (Martin \& Palumbi 1993; Evans et al. 2012). In conservation science, 
generation lengths have been used as a proxy for climate-change adaptability in species (Pearson et al. 2014; Bay et al. 2018; Foden et al. 2019), incorporated into assessments of sustainability of bycatch (Dillingham 2010) and utilised for scaling population declines when measuring extinction risk (Mace et al. 2008). Calculating generation length requires age- and sex-specific information on survival and fecundity, best calculated from a 'life table' (IUCN 2019) or by using proxies based on age of first reproduction $(F)$, maximum longevity $(L)$ and annual adult survival $(S)$ (Fung \& Waples 2017; IUCN 2019). However, collection and publication of age-based vital-rate information peaked in the $1980 \mathrm{~s}$ (Fung \& Waples 2017), and reporting of life-history data such as $F, L$ and $S$ is also likely to be declining in birds, with recovery rates of marked individuals falling (Robinson et al. 2009). Attempts to calculate generation lengths are therefore often hampered by a lack of appropriate life history data, but approaches exist for extrapolating or imputing $F, L$ and $S$ from data for other species (Di Marco et al. 2012; Pacifici et al. 2013; Cooke et al. 2018).

Birds are among the best-studied taxa (Titley et al. 2017), yet to date generation lengths have not been systematically estimated for all species across the group. The conservation status of birds has been more thoroughly assessed than that of any other taxonomic group (BirdLife International 2018a). They were the first class to be comprehensively assessed on the IUCN (International Union for Conservation of Nature) Red List of Threatened Species (hereafter the Red List; Collar \& Andrew 1988), the most widely adopted tool for assessing species' vulnerability to extinction (Mace et al. 2008). Birds have subsequently been comprehensively reassessed for the Red List six times (no other group has been assessed more than twice). Status assessments of birds have been central to highlighting the world's most threatened species, identifying impacts, directing conservation actions and charting trends in biodiversity (BirdLife International 2018a). Given this prominence, work is ongoing to improve estimates of the parameters underlying the Red List assessments for birds, of which generation length is important.

The Red List assigns species to categories of relative extinction risk using quantitative criteria based on their population sizes, trends and distribution (IUCN 2012). Rapid rates of population decline are associated with elevated extinction risk when scaled by generation length ( $O^{\prime}$ Grady et al. 2008). This 
scaling accounts for varying life history strategies and is used when assessing population declines on the Red List. This is particularly important under Red List Criterion A, which considers declines over 10 years or three generations, whichever is longer, and Criterion $\mathrm{C}$, which considers population size, structure and trends scaled by generation length (IUCN 2012). As generation lengths have hitherto not been estimated systematically and consistently for all bird species on the Red List, we use available data to estimate $F, L$ and $S$ for all birds, and from these parameters we derive estimates of generation lengths. We then assess the implications for the Red List, in terms of the number of species qualifying within each category, when trends are scaled over three generations using our new estimates. Finally, we consider the broader implications of our results.

\section{Methods}

\section{Data collation and modelling}

We compiled a dataset of published values for $F, L$ and $S$ from a variety of sources (see Appendix S1). We compared two approaches for assigning values to species lacking a published estimate. First, we used a hierarchical extrapolation approach. We calculated genus, family and order means of $F, L$ and $S$ from published values and followed a taxonomic hierarchy to extrapolate missing values: when a species lacked a published estimate, but published estimates existed for one or more congener(s), the median of those values was assigned; when there were no published estimates for the entire genus, the mean of other values for the family were used; and when there were no published estimates for the entire family, the mean of other values for the order were used (Appendix S2). To test the strength of this approach, we compared each $(i)$ published $(P)$ value of $F, L$ and $S$ with predicted genus, family and order means recalculated without $P i$. We calculated $R^{2}$ between the published and predicted values.

Second, we used a modelling approach. $F, L$ and $S$ are known to be correlated with a range of species traits, including body size and constraints associated with the environments that species inhabit 
(Partridge \& Harvey 1988; Sæther \& Bakke 2000). We used selected avian species traits (Appendix S3) to model variation in $F, L$ and $S$ as a function of species traits, and used the resulting models to generate predicted $F, L$ and $S$ values for species that lacked published values, but where trait data were available. To do this, we fitted Generalized Linear Mixed Models (GLMMs) with nested random effects for order, family and genus to account for phylogenetic correlations, and body mass (logtransformed), migratory status, environmental associations (marine, freshwater or terrestrial) and diet as fixed effects for each of the three response parameters. We also included breeding range centroid latitudes (as absolute values, derived from BirdLife's global species distribution maps) as a fixed effect to account for tropical species often having slower life histories (Wiersma et al. 2007), and mean clutch size for a subset of species where estimates were available ( $N=2156$ of 2401 species with data on $F, L$ and/or $S$ ). We centred and standardized all continuous predictors prior to analysis and used a version of Akaike information criterion (AICc) to compare all possible fixed-effect combinations of the global model and select the best model for each response parameter (Table 1). In cases where multiple models were within $2 \Delta \mathrm{AIC}_{\mathrm{c}}$ of the top-ranked model, we selected the model with the fewest parameters following the principle of parsimony (Arnold 2010). For $S$, we applied a logit transformation to normalize the response, while $F$ and $L$ were log-transformed and modelled as Gaussian responses (Quinn \& Keough 2002). All models were fitted in R statistics version 3.3.1 using package 'Ime4' (Bates et al. 2015). We checked residual diagnostic plots to determine data conformity to model assumptions, and used conditional and marginal $R^{2}$ values to evaluate the explanatory power of the best models (Fig. 1), calculated using methods described in Nakagawa \& Schielzeth (2013). Having confirmed that the models performed adequately in explaining observed variation in $F, L$ and $S$ across species in the dataset (Table 2), we used the best models to predict values $F, L$ and $S$ for all species where relevant trait data were available. Complete data for all traits listed above were available for 9,484 species worldwide (Appendix S3), with the exception of clutch size, which was missing for 3,386 of those species. For species lacking clutch size data, we used the best model from a candidate set excluding clutch size to derive predicted values of $F, L$ and $S$. For the remaining 1,642 species lacking data on two or more necessary traits for model prediction, we 
assigned values of $F, L$ and $S$ using the means of other species in that genus, family or order, depending on availability (i.e. hierarchical extrapolation).

Having calculated the coefficient of determination between 1) published and extrapolated, and 2) published and modelled values of $F, L$ and $S$, we compared the $R^{2}$ statistics to determine which approach generated values that best fitted the published data (Fig. 1).

\section{Calculating generation lengths}

We used the model-predicted values of $F, L$ and $S$ (Appendix S2) to estimate generation length in two ways: generation length based on $F, L$, and $S\left(G_{F L S ;}\right.$ equation 1) and generation length based on $F$ and $L\left(G_{F L}\right.$; equation 2).

$$
G_{F L S}=\sum_{x=F}^{L} x l_{x} / \sum_{x=F}^{L} l_{x}
$$

where $x$ is age in years, and the summations are from age $(x)$ of first reproduction $(F)$ to maximum longevity $(L)$; and $l_{x}$ is survivorship up to age $x$ (i.e. $l_{x}=S_{0} \cdot S_{I} \cdots S_{x-l}$ where $S$ is annual survival rate, and $l_{0}=1$ by definition; IUCN, 2019). Here we assumed $l_{x}=S^{x}$ (see below).

$$
G_{F L}=F+z(L-F)
$$

where $z$ is a number between 0 and 1 (IUCN 2019). To calculate $z$, we first used Equation 1 for species with published values of $F, L$, and $S$. From these, we excluded species with $S<0.3$ or $S^{L}<10^{-5}$ because $S$ is very likely underestimated for these species (see Discussion). This left 550 species, for which we calculated $z$ using Equation 3: 


$$
z=\left(G_{F L S}-F_{\max }\right) /\left(L_{\max }-F_{\max }\right)
$$

where $F_{\max }$ and $L_{\max }$ are, for each species, the maximum of either the observed value or the modelled value. We calculated the average value of $z$ for 4 groups (see Table 3), based on published $F$, and used these average values in Equation 2 to calculate $G_{F L}$ for all species.

Equation 1 is simplified from the definition of $G$ as the average age of parents (item 1 in IUCN 2019, section 4.4) to accommodate lack of age-specific survival and fecundity $(m)$ values. It assumes that fecundity is zero for ages $<F$ and $>L$, and that annual rates of fecundity and survival do not change with age from age $F$ to age $L$. As a result, Equation 1 does not include $m$, because it can be taken out of summation in both numerator and denominator and thus cancelled. We also assumed that annual survival rate from birth to age $F$ (which does not change the calculation of $G$ ) is also $S$, resulting in the simplification $l_{x}=S^{x}$. Because Equation 1 can underestimate generation length under certain conditions (see Discussion), and because this may also affect the calculation of $z$ (as Eq. 3 uses $G_{F L S}$ ), we defined generation length of each species as the larger of the two estimates (Appendix S4):

$$
G=\max \left(G_{F L S}, G_{F L}\right)
$$

For each species, we also calculated the difference between the two estimates, $G_{F L}-G_{F L S}$, and $S^{L}$, which is an estimate of the proportion of individuals reaching age $L$ (see Discussion).

The definition of age is important for this calculation. We assume that the data sources we used are likely to define age such that an individual starting to breed (nesting, mating) at $<12$ months of age, in the breeding season after the one in which it fledged, is called one-year old, which is different from the definition used in the Red List Guidelines (IUCN 2019) and the workbook accompanying the guidelines. Therefore, we adjusted our methods to account for this difference.

An alternative formula for generation length is $G_{F S}=F+1 /(1-S)$ (IUCN 2019), or $F+1 /(1-S)-1$ with the definition of age used here. This formulation (also known as the adult mortality proxy) assumes that there is no senescence (i.e. survival and fecundity remain constant after age $F$ ), and therefore does 
not use the information on maximum longevity. Therefore $G_{F S}>G_{F L S}$ for all species. We did not use $G_{F S}$ because it would be a better estimate only for species for which $S$ is relatively well known and $L$ is unknown or underestimated — we do not believe this is the case for most bird species. In addition, the single value of $S$ often available for all adult age classes means that $G_{F S}$ ignores senescence; this is partially corrected by limiting the calculation of $G_{F L S}$ (Eq. 1) to a maximum age of $L$.

\section{Assessing Red List implications}

We used the current population trend estimates from BirdLife International's Red List assessments (BirdLife International 2018b) to estimate species trends over both 10 years and three generations (Appendix S5). These trend estimates represent a percentage population decline/increase over a period of 10 years or three generations, whichever is longer, with the latter based on estimates of generation time based on earlier, incomplete, extrapolations from known parameter values from a smaller number of species. Most trend estimates are in bands representing uncertainty around precise values (e.g. 30-49\% decline suspected over three generations) as they are based on sparse data, inference and expert opinion. In these cases, the true trend is believed to fall somewhere within the range, with plausible minimum and maximum values defined by the upper and lower limits of the banded range. We used $3 \times$ the current generation time on the Red List assessment as an initial trend period $\left(T_{i}\right)$. Minimum, median and maximum estimated trends were then extrapolated from $T_{i}$ to $T_{1}=10$ years, and $T_{2}=\max (10$ years, $3 G)$, whichever is longer, as stipulated in the Red List Criteria (IUCN 2012). Minimum and maximum trend estimates were derived as follows: for all species recorded as currently declining, quantified trends were used if available (which was true for most threatened and Near Threatened species). For species with a currently declining trend but that lack a quantified trend estimate, a minimum decline of $1 \%$ and maximum of $24 \%$ was inferred, on the basis that none of these species are listed as threatened or Near Threatened under Criterion A (Appendix S5), while species with a rate of decline of $\geq 25 \%$ over 10 years or three generations are candidates for Near Threatened or threatened status (IUCN 2019). Median estimates were calculated as the mid-point of 
the minimum and the maximum (if only a single value rather than a range was documented for the rate of decline in the Red List assessment for a particular species, this value was used for the minimum, median and maximum). We used both linear and exponential rates of change (IUCN 2019) to extrapolate trends, thereby generating two values for each minimum, median and maximum trend estimate for each species. Each species was given an overall minimum, median and maximum, using the highest of the respective values.

We compared the resultant trends against the thresholds for Red List Criteria A2-A4: $>80 \%$ decline $=$ Critically Endangered, $50-79 \%$ decline $=$ Endangered, $30-49 \%$ decline $=$ Vulnerable $($ IUCN 2012 $)$, and a derived threshold of $25-29 \%$ decline $=$ Near Threatened. We quantified the number of species qualifying in threatened and Near Threatened categories under Criterion A for the different scenarios, and the number qualifying as threatened or Near Threatened overall when all Red List Criteria are applied.

\section{Results}

Estimating $F, L$ and $S$

As with other taxa, information on $F, L$ and $S$ was lacking for most birds. We found published estimates for just $13.1 \%, 18.0 \%$ and $8.4 \%$ of the world's 11,126 extant bird species respectively (Appendix S1). Hierarchical extrapolation allowed us to generate missing values of $F$ for 11,093 (99.7\%), $L$ for 11,097 (99.8\%) and $S$ for 10,936 (98.3\%) of all species (Appendix S2). However, extrapolated values were poorer at predicting published estimates than were modelled values (Fig. 1). Marginal and conditional $\mathrm{R}^{2}$ values indicated that species traits explained between $48 \%$ and $63 \%$ of between-species variance in $F, L$ and $S$, while nested phylogenetic random effects explained a further $18-27 \%$ of variance (Table 2). The best model for survival $(S)$ included positive effects of body mass and association with marine habitats, negative effects of clutch size and migratory status, and significant variation among dietary guilds (Table 1a). Body mass, clutch size, marine association and 
diet had similar effects on $F$ and $L$ (Table $1 \mathrm{~b} \& \mathrm{c}$ ), whereas the best model for $F$ also included a negative effect of freshwater associations (Table $1 \mathrm{~b}$ ), and for $L$ a positive effect of range latitude (Table 1c).

\section{Generation lengths and Red List implications}

The median generation length (from Equation 4) was found to be 2.99 years, with a range from 1.42 (Double-barred Finch Taeniopygia bichenovii) to 27.87 years (Southern Royal Albatross Diomedea epomophora) (Table 4). For 6,814 species (61\%), generation length is $<3.33$ years (Appendix S4), so population trends should be assessed over 10 years under Red List Criterion A. All other species require a longer period over which to assess trends. We estimate that in the absence of calculated generation lengths, assessing trends over the period of 10 years (which was used historically in the absence of calculated generation times) would underestimate the number of species qualifying as threatened or Near Threatened on the Red List based on population decline alone (Appendix S5). Using median estimates of decline over 10 years, 156 fewer species would qualify as threatened or Near Threatened under Criterion A than when declines are measured over the longer of 10 years or three generations, equivalent to $6.2 \%$ of threatened and Near Threatened bird species listed on the 2018 Red List (Fig. 2). Overall, however, when all Red List Criteria are considered, 2,014 species (18.5\%) qualify as threatened or Near Threatened when declines are assessed over 10 years, versus 2,116 (19.4\%) when 10 years or three generations are used (i.e. 102 species fewer).

\section{Discussion}

\section{Estimating $F, L$ and $S$}

Life history data are lacking for most species. We found it necessary to use data from well-studied species for supporting assessments of less well-known taxa (IUCN 2019). Even then, we could not use age-specific survival and fecundity rates (see below). It is important that a reliable approach is 
used to fill missing values for $F, L$ and $S$. Cooke et al. (2018) found that body mass was twice as important as phylogeny when predicting generation length in antelopes, and therefore recommended that extrapolations should not be based solely on taxonomy for these taxa. For birds, we found that hierarchical extrapolation was a poorer predictor of published values of $F, L$ and $S$ than our preferred model (Fig. 1), supporting the assertion that allometric and ecological data should be included when predicting life histories and generation lengths (Cooke et al. 2018). We provide a global dataset of $F$, $L$ and $S$ for all birds (Appendix S2).

\section{Calculating generation length}

For most bird species it is believed that the probability of an individual dying is independent of their age (a Type II survivorship curve; Pinder et al., 1978), at least for adults, so we made the assumptions in $G_{F L S}$ of constant fecundity and survival between the ages of first reproduction and maximum longevity. Although invalid for many species because survival and fecundity change gradually with age (Jones et al. 2014), the pattern of change with age is unknown for almost all bird species (Sæther $\&$ Bakke 2000).

Assuming that annual survival rate is constant from birth to age $L$, the proportion of individuals reaching age $L$ is $S^{L}$. If $S^{L}$ is a very small number, this may indicate that $S$ is underestimated. For example, if $S^{L}=10^{-7}$, then observing an individual as old as $L$ would require observing millions of individuals. Since such a large sample size is unlikely, $S$ may have been underestimated, resulting in an underestimated generation length. This may happen in various ways: if survival rate declines with age, and $S$ is estimated based mostly on data from older adults. It may also happen if $S$ is apparent survival, which means it does not include a correction for emigration (Ryu et al. 2016). Finally, $S$ may underestimate adult survival rate if it is based on a mixture of juvenile and adult birds, as juveniles have a lower survival rate (Benson et al. 2018). 
To avoid underestimation of generation length, we estimated $G$ as the larger of two values, $G_{F L S}$ and $G_{F L}$. This affected few species: $G_{F L}-G_{F L S}>1$ for only 545 species ( $4.9 \%$ of all species). For these 545 species, $S^{L}$ ranged from $10^{-25}$ to 0.039 (average=0.002). In other words, using $G_{F L}$ made a nonnegligible difference to the result only for species for which $S^{L}$ was low. As discussed, we suspect that $S$ is underestimated for many of these species (resulting in an underestimated $G_{F L S}$ ). The impact of this underestimation is minimized by use of the larger of $G_{F L S}$ and $G_{F L}$, but not negated entirely when $L$ has been underestimated. Overall, we assume that divergences from the assumption that fecundity is constant between $F$ and $L$ cancel out - i.e. any tendency to underestimate $L$ because of age-related biases in mark-recapture studies (Mills 2016) or lower fecundity in younger birds, particularly in long-lived species (Curio 1983), is cancelled out by senescence (Nussey et al. 2008). Also, although Cooke et al. (2018) argued that $L$ should only be estimated from wild animals, we have used all longevity data available: current research suggests that longevity is species specific and is mediated partly by genetics and partly by environmental stressors (Vágási et al. 2019). Captivity can be considered the benign end of a continuum, rather than a condition that cannot be replicated in nature, and we assume that including estimates of longevity from captive individuals biases the results upwards no more than a failure to discover the oldest breeding individuals in wild populations biases the results downwards.

The method developed here has attempted to control for variation between particularly well- or poorly-studied species. It is not easy to assess the effectiveness of our approach, but some generation lengths intuitively seem lower or higher than expected. For example, we found no published estimates of $F, L$, or $S$ for any of the four Pseudobulweria petrel species. Their mean generation length of 6.1 years is the lowest of any genus in the Procellariidae, half that of the family mean of 12.3 years, and well below the mean generation length of their phylogenetic sister-group Puffinus (Bretagnolle \& Pasquet 1998) of 12.7 years (Appendix S4). Of the 17 species in the genus Apus, the generation length of Common Swift A. apus ( 8.0 years) is $82 \%$ higher than the genus mean (4.4 years), while all generation lengths of the other 16 species fall within $17 \%$ of the mean. Similarly, of the 99 species in the genus Zosterops, the generation length of Silvereye Z. lateralis (3.5 years) is $74 \%$ higher than the 
genus mean (2.0 years), while all other species' generation lengths are within $22 \%$ of the mean. Interestingly, in Google searches for "scientific name" for each species in Apus and Zosterops, Common Swift and Silvereye rank first in their genera for number of hits - a proxy for interest (Nghiem et al. 2016). For both species, generation length came from $G_{F L}$ and they had longevity estimates far in excess of any congeners (Appendix S4). These examples suggest that estimates of generation length (and in particular maximum longevity) of well-studied species may exceed those of the majority of closely related species, and that generation length may hence have been underestimated for many species. Therefore, as new life history data become available, our generation length estimates should be updated to improve their accuracy. Among these, the highest priorities to investigate are those species that have generation length derived from modelled values that are significantly shorter than species in the same subfamily for which data was available: 394 species have values falling below others within their subfamily by more than $50 \%$ (Appendix S4) and require attention before their use in Red List assessments.

\section{Generation lengths and Red List implications}

After population size, trends are the best predictor of time to extinction, when scaled by generation length (O'Grady et al. 2008). For birds, scaling population trends by generation length has only a modest impact on their estimated overall risk of extinction. The fixed-length period of 10 years appears to be a remarkably good proxy for biological scaling of rates of decline in birds, being very close to the average of three generation lengths. However, for some families, genera and species, it has a substantial impact. Of the 52 species whose rates of decline exceed the threshold for listing as Critically Endangered under Criterion A when measuring trends over the longer of three generations or 10 years, only $30(58 \%)$ would qualify as CR under Criterion A if trends were measured over 10 
years. For example, an additional 8 of 22 albatrosses Diomedeidae qualify as threatened or Near Threatened under Criterion A when generation lengths are used to scale trends. The number of cockatoos Cacatuidae qualifying as threatened or Near Threatened only increases from seven to eight when trends are scaled by generation length, but the number of species qualifying as Critically Endangered or Endangered increases from two to six. Incorporating generation lengths in conservation assessments in this way has obvious consequences for policy and management. Multilateral conventions such as the Convention on Migratory Species, the Agreement on the Conservation of Albatrosses and Petrels (ACAP) and the Convention on International Trade in Endangered Species (CITES) were created to address the elevated extinction risk faced by particular suites of species - extinction risks that are best evaluated by scaling population trends by generation lengths.

The vast majority of bird species' populations and distributions considerably exceed the thresholds for qualifying as threatened under Criteria B, C or D of the Red List. However, many of these currently Least Concern species are declining (3,004/7,719 Least Concern species with known direction of trend $=38.9 \%$; BirdLife International 2018b) Given the widespread and pervasive threats facing birds worldwide, it is not unreasonable to expect that the majority of genuine Red List category changes in future will be species in this pool qualifying for uplisting to higher categories of threat as rates of population decline increase and exceed Red List category thresholds. To date this has not been the case (de L. Brooke et al. 2008; Monroe et al. 2019), but early assessments of birds lacked estimates of generation length for scaling trends. The availability of a global dataset from this study and the incorporation of these new generation lengths into BirdLife's Red List assessments will improve their consistency and accuracy. Approaches like monitoring rates of habitat change and inferring rates of population change for associated species (e.g. Bird et al. 2012; Tracewski et al. 2016), calculating changes in population abundance from citizen-science monitoring (e.g. Wotton et al. 2017; Gregory et al. 2019), and modelling future rates of change from mechanistic studies of the impacts of climate change on species (e.g. Foden et al. 2019; Wauchope et al. 2017) will all allow for improved assessments of extinction risk when generation lengths are used to scale population trends. 
In conclusion, this is the first study to calculate generation lengths for all the world's birds: a dataset that provides a comprehensive resource for avian life history studies. Our method for imputing missing life history data and minimising the impacts of data limitations on generation length estimates is not bird-specific and could usefully be applied to other taxa.

\section{Acknowledgments}

We thank the following individuals for contributing data or advice: Mark Balman, Peter Bennett, Maria Dias, Innes Sim, James Westrip and Hannah Wheatley. We also thank the many thousands of individuals and organisations who contribute to BirdLife's assessments of extinction risk for the IUCN Red List. Stony Brook University OVPR Seed Grant Program supported H.R.A.

\section{Supporting Information}

Published values of $F, L$ and $S$ and the original source (Appendix S1), published (observed), modelled and extrapolated values of $F, L$ and $S$ (Appendix S2), a database of avian life-history traits recorded for individual species (Appendix S3), calculated $G_{F L S}, G_{F L}, G_{F S}$ and $G$ for all birds (noting those considered priorities for research prior to the adoption of the $G$ for Red List assessments) (Appendix S4), and revised Red List trend estimates with predicted qualifying Red List categories for all birds (Appendix S5) are available online. The authors are solely responsible for the content and functionality of these materials. Queries (other than absence of the material) should be directed to the corresponding author. 


\section{Literature cited}

Arnold TW. 2010. Uninformative parameters and model selection using Akaike's Information Criterion. The Journal of Wildlife Management 74:1175-1178.

Bates D, Mächler M, Bolker B, Walker S. 2015. Fitting Linear Mixed-Effects Models Using lme4. Journal of Statistical Software 67.

Bay RA, Harrigan RJ, Underwood VL, Gibbs HL, Smith TB, Ruegg K. 2018. Genomic signals of selection predict climate-driven population declines in a migratory bird. Science 359:83-86.

Benson JF, Jorgensen SJ, O’Sullivan JB, Winkler C, White CF, Garcia- Rodriguez E, SosaNishizaki O, Lowe CG. 2018. Juvenile survival, competing risks, and spatial variation in mortality risk of a marine apex predator. Journal of Applied Ecology 55:2888-2897.

Bird JP, Buchanan GM, Lees AC, Clay RP, Develey PF, Yépez I, Butchart SHM. 2012. Integrating spatially explicit habitat projections into extinction risk assessments: a reassessment of Amazonian avifauna incorporating projected deforestation: Extinction risk of Amazonian avifauna. Diversity and Distributions 18:273-281.

BirdLife International. 2018a. State of the world's birds: taking the pulse of the planet. Cambridge, UK: BirdLife International.

BirdLife International. 2018b. IUCN Red List for birds. http://datazone.birdlife.org/species/search Bretagnolle V, Pasquet E. 1998. Cytochrome-B Evidence for Validity and Phylogenetic Relationships of Pseudobulweria and Bulweria (Procellariidae). The Auk 115:188-195.

Collar NJ, Andrew P. 1988. Birds to watch. International Council for Bird Preservation, Cambridge, UK.

Cooke RS, Gilbert TC, Riordan P, Mallon D. 2018. Improving generation length estimates for the IUCN Red List. PloS one 13:e0191770.

Curio E. 1983. Why de young birds reproduce less well? Ibis 125:400-404.

de L. Brooke M, Butchart SHM, Garnett ST, Crowley GM, Mantilla-Beniers NB, Stattersfield AJ. 2008. Rates of Movement of Threatened Bird Species between IUCN Red List Categories and toward Extinction. Conservation Biology 22:417-427. 
De Magalhães JP, Costa J. 2009. A database of vertebrate longevity records and their relation to other life- history traits. Journal of Evolutionary Biology 22:1770-1774.

Di Marco M, Cardillo M, Possingham HP, Wilson KA, Blomberg SP, Boitani L, Rondinini C. 2012. A novel approach for global mammal extinction risk reduction: Global mammal extinction risk reduction. Conservation Letters 5:134-141.

Dillingham PW. 2010. Generation time and the maximum growth rate for populations with agespecific fecundities and unknown juvenile survival. Ecological Modelling 221:895-899.

Evans AR et al. 2012. The maximum rate of mammal evolution. Proceedings of the National Academy of Sciences 109:4187-4190.

Foden WB et al. 2019. Climate change vulnerability assessment of species. Wiley Interdisciplinary Reviews: Climate Change 10:e551.

Fung HC, Waples RS. 2017. Performance of IUCN proxies for generation length. Conservation Biology 31:883-893.

Gaillard J - M., Yoccoz NG, Lebreton J - D., Bonenfant C, Devillard S, Loison A, Pontier D, Allaine D. 2005. Generation Time: A Reliable Metric to Measure Life- History Variation among Mammalian Populations. The American Naturalist 166:119-123.

Garnett ST et al. 2015. Biological, ecological, conservation and legal information for all species and subspecies of Australian bird. Scientific Data 2:150061.

Gregory RD, Skorpilova J, Vorisek P, Butler S. 2019. An analysis of trends, uncertainty and species selection shows contrasting trends of widespread forest and farmland birds in Europe. Ecological Indicators 103:676-687.

IUCN. 2012. IUCN Red List Categories \& Criteria. Version IUCN Red List Categories and Criteria: Version 3.1. Second edition. Gland, Switzerland and Cambridge, UK: IUCN. iv + 32pp.3.1 Second edition.

IUCN. 2019. Guidelines for Using the IUCN Red List Categories and Criteria. Version 13. Prepared by the Standards and Petitions Subcommittee. Downloadable from http://www.iucnredlist.org/documents/RedListGuidelines.pdf. 
Jones OR et al. 2014. Diversity of ageing across the tree of life. Nature 505:169-173.

Mace GM, Collar NJ, Gaston KJ, Hilton-Taylor C, Akçakaya HR, Leader-Williams N, Milner-

Gulland EJ, Stuart SN. 2008. Quantification of Extinction Risk: IUCN's System for

Classifying Threatened Species. Conservation Biology 22:1424-1442.

Martin AP, Palumbi SR. 1993. Body size, metabolic rate, generation time, and the molecular clock. Proceedings of the National Academy of Sciences 90:4087-4091.

Mills AM. 2016. Banding data reveal bias in age- class sampling of songbirds during spring migration. Journal of Field Ornithology 87:323-336.

Monroe MJ, Butchart SHM, Mooers AO, Bokma F. 2019. The dynamics underlying avian extinction trajectories forecast a wave of extinctions. Biology Letters 15:1-5.

Myhrvold NP, Baldridge E, Chan B, Sivam D, Freeman DL, Ernest SKM. 2015. An amniote lifehistory database to perform comparative analyses with birds, mammals, and reptiles: Ecological Archives E096-269. Ecology 96:3109-000.

Nakagawa S, Schielzeth H. 2013. A general and simple method for obtaining R2 from generalized linear mixed-effects models. Methods in Ecology and Evolution 4:133-142.

Nghiem LTP, Papworth SK, Lim FKS, Carrasco LR. 2016. Analysis of the Capacity of Google Trends to Measure Interest in Conservation Topics and the Role of Online News. PLOS ONE 11:e0152802.

Nussey DH, Coulson T, Festa- Bianchet M, Gaillard J-M. 2008. Measuring senescence in wild animal populations: towards a longitudinal approach. Functional Ecology 22:393-406.

O’Grady JJ, Reed DH, Brook BW, Frankham R. 2008. Extinction risk scales better to generations than to years. Animal Conservation 11:442-451.

Pacifici M, Santini L, Di Marco M, Baisero D, Francucci L, Marasini GG, Visconti P, Rondinini C. 2013. Generation length for mammals. Nature Conservation 5:87-94.

Partridge L, Harvey PH. 1988. The Ecological Context of Life History Evolution. Science 241:14491455.

This article is protected by copyright. All rights reserved. 
Pearson RG et al. 2014. Life history and spatial traits predict extinction risk due to climate change.

Nature Climate Change 4:217-221.

Pinder JE, Wiener JG, Smith MH. 1978. The Weibull Distribution: A New Method of Summarizing Survivorship Data. Ecology 59:175-179.

Quinn GP, Keough MJ. 2002. Experimental design and data analysis for biologists. Cambridge University Press, Cambridge.

Robinson RA, Grantham MJ, Clark JA. 2009. Declining rates of ring recovery in British birds. Ringing \& Migration 24:266-272.

Ryu HY, Shoemaker KT, Kneip É, Pidgeon AM, Heglund PJ, Bateman BL, Thogmartin WE, Akçakaya HR. 2016. Developing population models with data from marked individuals. Biological Conservation 197:190-199.

Sæther B-E, Bakke Ø. 2000. Avian life history variation and contribution of demographic traits to the population growth rate. Ecology 81:642-653.

Titley MA, Snaddon JL, Turner EC. 2017. Scientific research on animal biodiversity is systematically biased towards vertebrates and temperate regions. PLOS ONE 12:e0189577.

Tracewski Ł, Butchart SHM, Marco MD, Ficetola GF, Rondinini C, Symes A, Wheatley H, Beresford AE, Buchanan GM. 2016. Toward quantification of the impact of 21st-century deforestation on the extinction risk of terrestrial vertebrates. Conservation Biology 30:1070-1079.

Tuljapurkar S, Gaillard J-M, Coulson T. 2009. From stochastic environments to life histories and back. Philosophical Transactions of the Royal Society B: Biological Sciences 364:14991509.

Vágási CI, Vincze O, Pătraș L, Osváth G, Pénzes J, Haussmann MF, Barta Z, Pap PL. 2019. Longevity and life history coevolve with oxidative stress in birds. Functional Ecology 33:152-161.

Wasser DE, Sherman PW. 2010. Avian longevities and their interpretation under evolutionary theories of senescence. Journal of Zoology 280:103-155. 
Wauchope HS, Shaw JD, Varpe Ø, Lappo EG, Boertmann D, Lanctot RB, Fuller RA. 2017. Rapid climate-driven loss of breeding habitat for Arctic migratory birds. Global Change Biology 23:1085-1094.

Wiersma P, Muñoz-Garcia A, Walker A, Williams JB. 2007. Tropical birds have a slow pace of life. Proceedings of the National Academy of Sciences 104:9340-9345.

Wotton SR et al. 2017. Developing biodiversity indicators for African birds. Oryx 54:1-12.

Table 1 Results of model selection predicting annual adult survival (a), age at first reproduction (b) and maximum longevity (c) for the global avifauna ${ }^{a, b}$.

\begin{tabular}{|c|c|c|c|c|c|c|c|c|c|c|c|}
\hline a) & \multicolumn{3}{|c|}{ Annual adult survival $(S)$} & & & & & & & & \\
\hline Rank & Intercept & Diet & Forest & Freshwater & Marine & Migrant & Latitude & Clutch & Mass & $\triangle \mathrm{AIC}$ & $\mathrm{AlCW}$ \\
\hline 1 & 0.61 & + & & & 0.26 & -0.12 & & -0.31 & 0.44 & 0 & 0.24 \\
\hline 2 & 0.61 & + & & -0.05 & 0.27 & -0.12 & & -0.31 & 0.44 & 1.01 & 0.14 \\
\hline 3 & 0.63 & + & -0.04 & & 0.24 & -0.13 & & -0.31 & 0.44 & 1.48 & 0.11 \\
\hline 4 & 0.6 & + & & & 0.26 & -0.11 & -0.01 & -0.31 & 0.44 & 1.57 & 0.11 \\
\hline 5 & 0.64 & + & -0.05 & -0.06 & 0.26 & -0.12 & & -0.31 & 0.44 & 2.25 & 0.08 \\
\hline 6 & 0.61 & + & & -0.05 & 0.28 & -0.1 & -0.01 & -0.3 & 0.44 & 2.58 & 0.07 \\
\hline 7 & 0.63 & + & -0.04 & & 0.25 & -0.11 & -0.01 & -0.31 & 0.44 & 3.04 & 0.05 \\
\hline 8 & 0.64 & + & -0.05 & -0.06 & 0.26 & -0.11 & -0.01 & -0.3 & 0.44 & 3.79 & 0.04 \\
\hline 9 & 0.58 & + & & & 0.25 & & -0.03 & -0.31 & 0.44 & 3.91 & 0.03 \\
\hline 10 & 0.59 & + & & -0.06 & 0.27 & & -0.03 & -0.3 & 0.44 & 4.54 & 0.02 \\
\hline b) & \multicolumn{4}{|c|}{ Age at first reproduction $(F)$} & & & & & & & \\
\hline Rank & Intercept & Diet & Forest & Freshwater & Marine & Migrant & Latitude & Clutch & Mass & $\triangle \mathrm{AIC}$ & $\mathrm{AlCW}$ \\
\hline 1 & 0.16 & + & & -0.02 & 0.04 & & & -0.01 & 0.13 & 0 & 0.21 \\
\hline 2 & 0.16 & + & & -0.02 & 0.04 & & 0 & -0.01 & 0.13 & 0.28 & 0.18 \\
\hline 3 & 0.16 & + & & -0.02 & 0.04 & 0.01 & -0.01 & -0.01 & 0.13 & 1.92 & 0.08 \\
\hline 4 & 0.15 & + & 0 & -0.02 & 0.04 & & & -0.01 & 0.13 & 1.93 & 0.08 \\
\hline 5 & 0.15 & + & & -0.02 & 0.04 & 0 & & -0.01 & 0.13 & 2.04 & 0.07 \\
\hline 6 & 0.16 & + & 0 & -0.02 & 0.04 & & 0 & -0.01 & 0.13 & 2.17 & 0.07 \\
\hline 7 & 0.15 & + & & & 0.04 & & 0 & -0.01 & 0.13 & 2.31 & 0.07 \\
\hline 8 & 0.15 & + & & & 0.04 & & & -0.01 & 0.13 & 2.53 & 0.06 \\
\hline 9 & 0.15 & + & 0 & -0.02 & 0.04 & 0.01 & -0.01 & -0.01 & 0.13 & 3.8 & 0.03 \\
\hline 10 & 0.15 & + & 0.01 & & 0.04 & & 0 & -0.01 & 0.13 & 3.95 & 0.03 \\
\hline c) & \multicolumn{4}{|c|}{ Maximum longevity $(L)$} & & & & & & & \\
\hline Rank & Intercept & Diet & Forest & Freshwater & Marine & Migrant & Latitude & Clutch & Mass & $\triangle \mathrm{AIC}$ & $\mathrm{AlCW}$ \\
\hline 1 & 1.05 & + & & & 0.04 & & 0.02 & -0.04 & 0.13 & 0 & 0.29 \\
\hline 2 & 1.06 & + & -0.01 & & 0.04 & & 0.02 & -0.04 & 0.13 & 0.92 & 0.18 \\
\hline 3 & 1.05 & + & & -0.01 & 0.04 & & 0.02 & -0.04 & 0.13 & 1.8 & 0.12 \\
\hline
\end{tabular}

This article is protected by copyright. All rights reserved. 


\begin{tabular}{|c|c|c|c|c|c|c|c|c|c|c|c|}
\hline 4 & 1.05 & + & & & 0.04 & 0.01 & 0.02 & -0.04 & 0.13 & 1.8 & 0.12 \\
\hline 5 & 1.06 & + & -0.01 & -0.01 & 0.04 & & 0.02 & -0.04 & 0.13 & 2.54 & 0.08 \\
\hline 6 & 1.06 & + & -0.01 & & 0.04 & 0 & 0.02 & -0.04 & 0.13 & 2.79 & 0.07 \\
\hline 7 & 1.05 & + & & -0.01 & 0.04 & 0.01 & 0.02 & -0.04 & 0.13 & 3.55 & 0.05 \\
\hline 8 & 1.06 & + & -0.01 & -0.01 & 0.04 & 0.01 & 0.02 & -0.04 & 0.13 & 4.36 & 0.03 \\
\hline 9 & 1.06 & + & -0.02 & & & & 0.03 & -0.04 & 0.14 & 5.6 & 0.02 \\
\hline 10 & 1.05 & + & & & & & 0.03 & -0.04 & 0.14 & 6.37 & 0.01 \\
\hline
\end{tabular}

${ }^{a}$ The 10 top-ranked models (using AICc) for each response variable are shown, indicating the parameters included in the model and their coefficients (except for multi-level categorical predictors, where those marked "+" were included).

${ }^{b}$ All models included Order, Family and Genus as nested random effects.

Table 2 Explanatory power of models determined using methods of Nakagawa \& Schielzeth (2013) $a, b$.

\begin{tabular}{|l|c|c|}
\hline Response variable & Marginal $\boldsymbol{R}^{\mathbf{2}}$ & Conditional $\boldsymbol{R}^{\mathbf{2}}$ \\
\hline Annual adult survival $(S)$ & 0.581 & 0.767 \\
\hline Age at first reproduction $(F)$ & 0.629 & 0.890 \\
\hline Maximum longevity $(L)$ & 0.479 & 0.658 \\
\hline
\end{tabular}

${ }^{a}$ Marginal $\mathrm{R}^{2}$ values show the proportion of variance explained by fixed effects (in this case, species traits), while conditional $R^{2}$ shows the variance explained by fixed and random effects combined (i.e. including phylogeny).

${ }^{b}$ Values show the best models for each response from the candidate sets that included clutch size as a predictor.

Table 3: Mean $z$ values based on published values of $F$.

\begin{tabular}{|c|c|c|c|}
\hline $\boldsymbol{F}$ & Number of species & Mean z & StdDev of $\mathbf{z}$ \\
\hline $\mathbf{0 . 5 - 1 . 5}$ & 301 & 0.142 & 0.0536 \\
\hline $\mathbf{1 . 5 - 2 . 5}$ & 79 & 0.194 & 0.0748 \\
\hline $\mathbf{2 . 5 - 4 . 5}$ & 102 & 0.236 & 0.0697 \\
\hline $\mathbf{> 4 . 5}$ & 68 & 0.317 & 0.0602 \\
\hline
\end{tabular}

This article is protected by copyright. All rights reserved. 
Table 4: Families and species that have the longest and shortest generation lengths.

\begin{tabular}{|c|c|c|c|c|c|}
\hline \multicolumn{3}{|c|}{10 families with longest generation lengths } & \multicolumn{3}{|c|}{10 families with shortest generation lengths } \\
\hline Diomedeidae & Albatrosses & 21.73 & Pardalotidae & Pardalotes & 2.12 \\
\hline Struthionidae & Ostriches & 14.53 & Trochilidae & Hummingbirds & 2.09 \\
\hline Cacatuidae & Cockatoos & 13.94 & Viduidae & $\begin{array}{l}\text { Whydahs and } \\
\text { indigobirds }\end{array}$ & 2.05 \\
\hline Fregatidae & Frigatebirds & 13.39 & Estrildidae & Waxbills & 2.05 \\
\hline Cathartidae & New World vultures & 13.21 & Remizidae & Penduline-tits & 1.99 \\
\hline Pelecanidae & Pelicans & 12.56 & Phylloscopidae & Leaf-warblers & 1.98 \\
\hline Gruidae & Cranes & 12.51 & Polioptilidae & Gnatcatchers & 1.94 \\
\hline Stercorariidae & Skuas & 12.45 & Certhiidae & Treecreepers & 1.89 \\
\hline Phoenicopteridae & Flamingos & 12.35 & Regulidae & Kinglets and firecrests & 1.83 \\
\hline Procellariidae & Petrels, shearwaters & 12.26 & Elachuridae & Elachura & 1.82 \\
\hline \multicolumn{3}{|c|}{10 species with longest generation lengths } & \multicolumn{3}{|c|}{10 species with shortest generation lengths } \\
\hline $\begin{array}{l}\text { Diomedea } \\
\text { epomophora }\end{array}$ & $\begin{array}{l}\text { Southern Royal } \\
\text { Albatross }\end{array}$ & 27.87 & Atthis heloisa & $\begin{array}{l}\text { Bumblebee } \\
\text { Hummingbird }\end{array}$ & 1.59 \\
\hline Vultur gryphus & Andean Condor & 27.25 & Lonchura caniceps & Grey-headed Mannikin & 1.57 \\
\hline Cacatua galerita & $\begin{array}{l}\text { Sulphur-crested } \\
\text { Cockatoo }\end{array}$ & 27.21 & Taeniopygia guttata & Timor Zebra Finch & 1.57 \\
\hline $\begin{array}{l}\text { Phoebastria } \\
\text { immutabilis }\end{array}$ & Laysan Albatross & 26.70 & $\begin{array}{l}\text { Margaroperdix } \\
\text { madagarensis }\end{array}$ & Madagascar Partridge & 1.53 \\
\hline Diomedea sanfordi & $\begin{array}{l}\text { Northern Royal } \\
\text { Albatross }\end{array}$ & 25.97 & Colinus cristatus & Crested Bobwhite & 1.53 \\
\hline $\begin{array}{l}\text { Diomedea } \\
\text { antipodensis }\end{array}$ & Antipodean Albatross & 25.86 & Estrilda perreini & Black-tailed Waxbill & 1.50 \\
\hline Strigops habroptila & Kakapo & 25.82 & Perdix dauurica & Daurian Partridge & 1.49 \\
\hline Fulmarus glacialis & Northern Fulmar & 25.34 & Sublegatus obscurior & $\begin{array}{l}\text { Amazonian Scrub- } \\
\text { flycatcher }\end{array}$ & 1.46 \\
\hline Cacatua moluccensis & $\begin{array}{l}\text { Salmon-crested } \\
\text { Cockatoo }\end{array}$ & 24.19 & Rhipidura albicollis & White-throated Fantail & 1.44 \\
\hline $\begin{array}{l}\text { Thalassarche } \\
\text { melanophris }\end{array}$ & $\begin{array}{l}\text { Black-browed } \\
\text { Albatross }\end{array}$ & 23.61 & Taeniopygia bichenovii & Double-barred Finch & 1.42 \\
\hline
\end{tabular}


Figure 1: Published versus predicted values of $F, L$, and $S$ based upon taxon means from hierarchical extrapolation (above), and modelled values (below). Solid lines represent the plotted relationship between published and predicted values while dotted lines trace a perfect relationship.
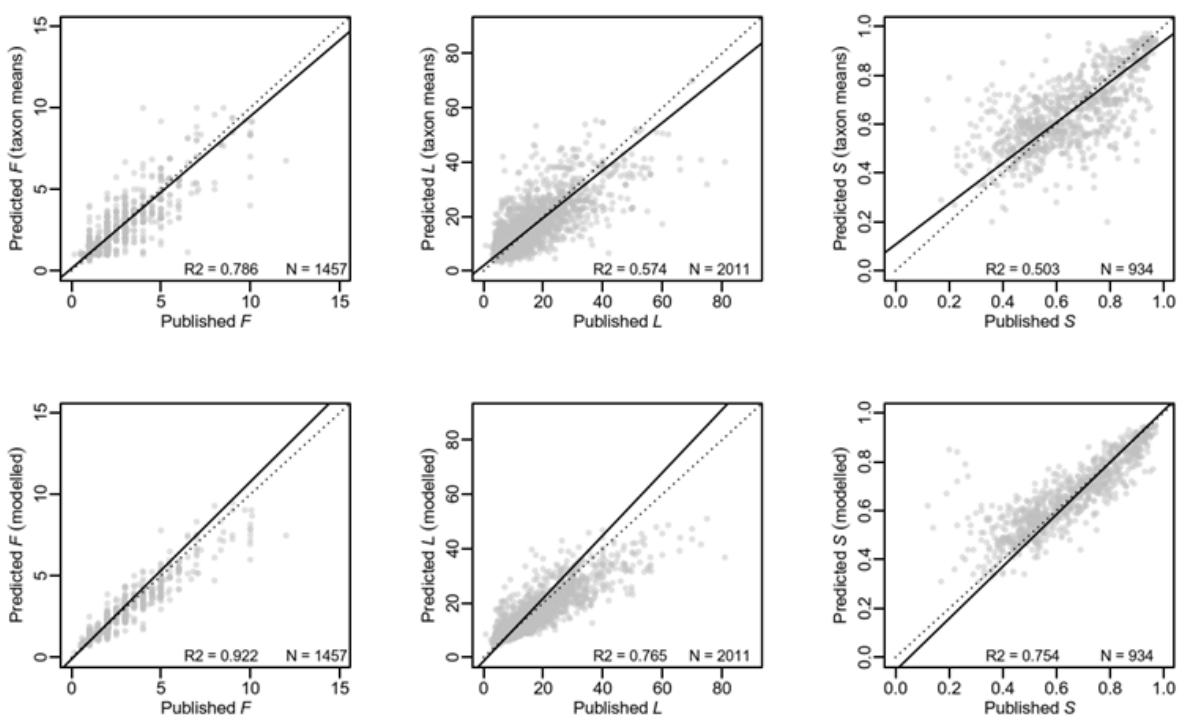

Figure 2: Red List implications of calculating trends over three generations using the newly estimated generation lengths: a) for species qualifying only owing to population declines under Criterion A; b) for species qualifying under any Red List Criteria. Bars show the number of species qualifying for each Red List category $(\mathrm{CR}=$ Critically Endangered, EN $=$ Endangered, $\mathrm{VU}=$ Vulnerable, $\mathrm{NT}=$ Near Threatened) when assessing trends over 10 years (black), three generations (grey).
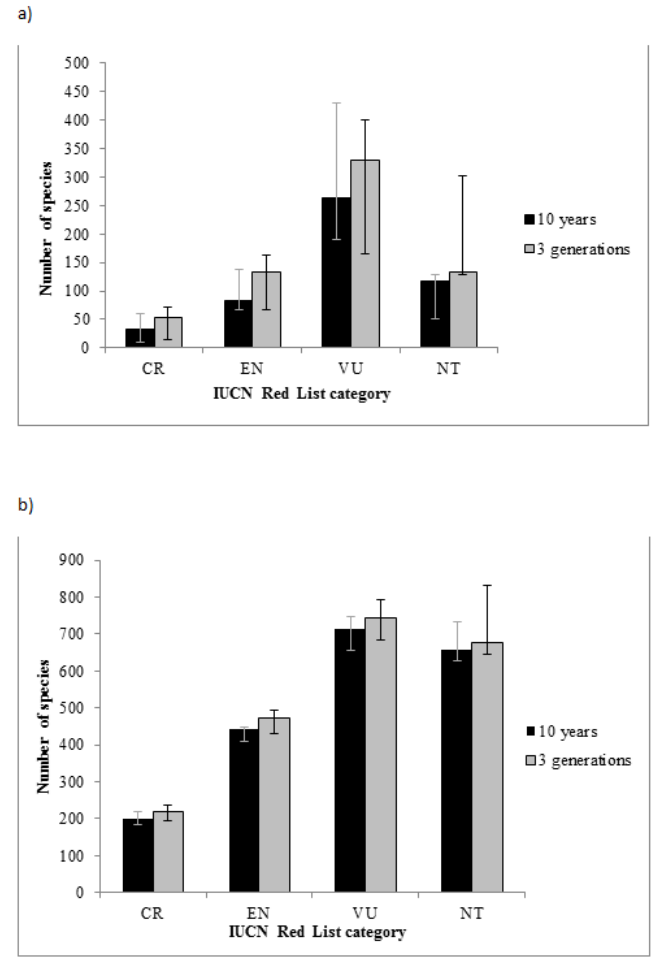